ORIGINAL ARTICLE

\title{
Comparative Study between Two Triple-therapy Regimens in Treating Helicobacter pylori: Related Peptic Ulcer Disease
}

\author{
Gokul D Yatheendranathan ${ }^{1}$, Sudhakar Ankaiya², J Lalith Kumar ${ }^{3}$
}

\begin{abstract}
Background: Helicobacter pylori (H. pylori) infection has increased worldwide and it is found to be positive in more than $50 \%$ of the specimens taken during endoscopy. The goal of the study is to compare the efficacy of two triple-therapy regimens in eradication of $H$. pylori and to evaluate the cost factor involved.

Aims:

- To compare and study between two triple-therapy regimens in treating (H. pylori)-related peptic ulcer disease.

- To find the cost efficacy between two triple-therapy regimens.

Materials and methods: A randomized single-blinded study was conducted at a tertiary care hospital from 2016 to 2018. Upper gastrointestinal endoscopy was performed on all the patients after spraying them with a topical local anesthetic agent (10\% lignocaine spray). Two biopsy specimens were taken from the antrum of the stomach. The rapid urease test (RUT) was considered positive, if a color change from yellow to pink was noted in the RUT kit within 10 minutes. The sample size was calculated and fixed at 60 . The RUT-positive patients were divided into two groups by computer-generated random allotment. Group I patients were started on regimen I comprising omeprazole 20 mg twice daily, clarithromycin $500 \mathrm{mg}$ twice daily, and amoxicillin 1,000 mg twice daily for 2 weeks. Group Il patients were started on regimen II: OCM: omeprazole $20 \mathrm{mg}$ twice daily, clarithromycin $500 \mathrm{mg}$ twice daily, and metronidazole $400 \mathrm{mg}$ twice daily for 2 weeks. The endoscopic RUT was performed in the beginning and after 6 weeks to check for eradication of H. pylori. The ethical committee approval was obtained (IEC no. 2017/308) and data were collected using a proforma and were entered in the Excel sheet. The statistical analysis was done by SPSS (version 23). Descriptive statistics regarding age, sex, and inference with regimens were calculated and recorded.
\end{abstract}

Results: Among the patients administered regimen I, H. pylori was eradicated in 27 (90\%). And among the patients administered regimen II, H. pylori was eradicated in $28(93.3 \%)$. This difference was not statistically significant with $p$ value of 0.323 . However, it was observed that regimen II was cheaper than regimen I.

Keywords: Comparison, Endoscopy, Helicobacter pylori, Triple-therapy.

SBV Journal of Basic, Clinical and Applied Health Science (2019): 10.5005/jp-journals-10082-02222

\section{INTRODUCTION}

The identification of Helicobacter pylori and its causative connection to peptic ulcer diseases and gastric adenocarcinomas has thoroughly transformed our understanding of these diseases. An increase in metaplasia and atrophy of the stomach mucosa has been found to be linked to the presence of $H$. pylori infections. Both the oxidative and nitrosative pressure in grouping with inflammation plays a key role in the carcinoma of stomach. ${ }^{1}$

Although immune cells normally identify and attack invading bacteria such as those accumulating as $H$. pylori infection, here they are unable to reach the stomach lining. In addition, $H$. pylori has developed different ways of interfering with local immune responses, making them ineffective in eliminating these bacteria. ${ }^{2,3}$

Helicobacter pylori is a risk factor for the carcinoma of stomach and its eradication reduces the risk of carcinoma. ${ }^{4}$ The treatment option of H. pylori has remained a great challenge for the past 25 years. The first stomach parietal cell proton pump inhibitor (PPI) (omeprazole) was used widely in treating peptic ulcer disease. The S-isomer of omeprazole is esomeprazole, which was the first single optical isomer to be introduced. ${ }^{5-9}$ On the former, esomeprazole had better results compared to other PPIs. ${ }^{10}$ Esomeprazole has an advanced level of action against $H$. Pylori when compared to other PPIs like omeprazole. Hence, these properties enhance the efficacy in the treatment of $\mathrm{H}$. pylorirelated peptic ulcer diseases. ${ }^{11-14}$

\footnotetext{
${ }^{1-3}$ Department of General Surgery, Shri Sathya Sai Medical College and Research Institute, Kancheepuram, Tamil Nadu, India
}

Corresponding Author: Gokul D Yatheendranathan, Department of General Surgery, Shri Sathya Sai Medical College and Research Institute, Kancheepuram, Tamil Nadu, India, Phone: +919003850396, e-mail: gokuldy@gmail.com

How to cite this article: Yatheendranathan GD, Ankaiya S, Kumar JL. Comparative Study between Two Triple-therapy Regimens in Treating Helicobacter pylori: Related Peptic Ulcer Disease. J Basic Clin Appl Health Sci 2019;2(3):108-111.

Source of support: Sri Balaji Vidyapeeth, Deemed University, Puducherry

Conflict of interest: None

The effectiveness for $H$. pylori treatment should have achieved more than $80 \%$ "intention-to-treat" (ITT) eradication rate. Triple therapy regimens along with one PPI were the first line of treatment of choice for more than two decades in the past. The traditional first line of treatment is with a PPI (two times a day), amoxicillin ( $1 \mathrm{~g}$ two times a day) or metronidazole (500 mg two times a day), and clarithromycin ( 250 or $500 \mathrm{mg}$ two times a day) for 7 days. This regimen was followed till the recently published report at the Maastricht III Consensus Conference held in $2007 .{ }^{15}$ Further revisions of this publication happened in the years 2012 and 2017. ${ }^{16,17}$

() The Author(s). 2019 Open Access This article is distributed under the terms of the Creative Commons Attribution 4.0 International License (https://creativecommons. org/licenses/by-nc/4.0/), which permits unrestricted use, distribution, and non-commercial reproduction in any medium, provided you give appropriate credit to the original author(s) and the source, provide a link to the Creative Commons license, and indicate if changes were made. The Creative Commons Public Domain Dedication waiver (http://creativecommons.org/publicdomain/zero/1.0/) applies to the data made available in this article, unless otherwise stated. 


\section{Materials and Methods}

A randomized single-blinded study was conducted at a tertiary care hospital from 2016 to 2018. By universal sampling technique, 60 patients were included in the study as per inclusion and exclusion criteria. The rapid urease test (RUT) and endoscopy were the parameters of assessment. A total of 60 patients who were positive for $\mathrm{H}$. pylori after endoscopy and RUT were divided into two treatment regimens by computer-generated random table number allotment.

Regimen I: OCA: omeprazole (20 mg BD), clarithromycin (500 mg BD), and amoxicillin (1000 mg BD) for 2 weeks.

Regimen II: OCM: omeprazole (20 mg BD), clarithromycin (500 $\mathrm{mg} \mathrm{BD}$ ), and metronidazole (400 mg BD) for 2 weeks.

A RUT during endoscopy was performed after 6 weeks of therapy in patients of both groups to check for eradication of H. pylori.

\section{Inclusion Criteria}

- Patients with history of dyspepsia, malena, and/or hematemesis

- Patients having evidence of H. pylori infection by RUT

\section{Exclusion Criteria}

- Age less than 16 and more than 80 years

- Pregnant women or lactating women

- Carcinoma or pyloric stenosis on endoscopy

- Cirrhosis

Upper gastrointestinal endoscopy was performed on all the patients after an overnight fasting. Two biopsy specimens were taken from the antrum of the stomach and RUT was done. A positive response was recorded if there was a colour change from yellow to pink in the RUT kit within 10 minutes.

\section{Statistical Methods}

The data were collected using a predetermined proforma and followed up for 6 weeks. The data collected were entered through the Excel sheet and the statistical analysis using the SPSS software (version 23) was carried out. Descriptive statistics such as frequency and percentage were calculated. Continuous variables were expressed in mean and standard deviation. Association between various study variables was done by the Chi-square test. A $p$ value of 0.05 or less was taken to indicate a significant difference. Description of statistics: comparison of two triple therapy regimens using the independent sample test.

\section{Ethical Consideration}

After obtaining an informed and written consent, the study was conducted. Institutional ethical committee approval was obtained (IEC no. 2017/308) and the copy of the approval is attached in the annexure.

\section{Results}

\section{Descriptive Statistics}

\section{Age Distribution}

In the study population, mean age of the participants was 41.23 with age ranging from 18 to 68 . We observed that the patients of third to fifth decade were more affected with $H$. pylori.

\section{Association of Gender with Regimen}

The proportion of males in the treatment regimen II was high compared to the females and vice versa. This difference was not statistically significant with the $p$ value of 0.29 .

\section{Regimen Inference}

Among the group I patients administered regimen I, H. pylori was eradicated in 27 (90\%) and among the group II patients administered regimen II, H. pylori was eradicated in 28 (93.3\%). This difference was not statistically significant with $p$ value of 0.323 .

\section{Discussion}

A total of 60 patients were included in the study, with ages ranging from 18 and 68. Majority were females with $57 \%$ and $43 \%$ were males. Among them, endoscopic findings suggestive of acid peptic disease were observed in 27 (45\%) patients and GERD in 9 (15\%).

Among the 60, 30 patients were administered regimen I, with eradication rate of $90 \% .^{18}$ Regimen II was administered for the other 30 patients, and an eradication rate of $93.3 \%{ }^{18}$ was observed after 6 weeks. This difference was found to be not statistically significant with a $p$ value of 0.323 . This result correlates well with similar other studies.

In a study by Khanal et al., where Tinidazole was used instead of metronidazole for 2 weeks on 80 patients, it was observed that the eradication rates of regimen I and II were 93.8 and $91.4 \%$, respectively. ${ }^{17}$

In the OPTRICON study, Molina-Infante et al. found that addition of metronidazole ( $400 \mathrm{mg}$ twice daily) to empirical triple therapy [esomeprazole (40 mg twice daily), amoxicillin ( $1 \mathrm{~g}$ twice daily), and clarithromycin (500 mg twice daily) for 2 weeks] had increased eradication rates by $10 \%$. They also said that addition of metronidazole resulted in increased adverse effects. ${ }^{19}$

Alsohaibani et al., in their prospective trial conducted in Saudi Arabia, compared the traditional triple therapy ( 2 weeks) with the sequential therapy (10 days) for treatment of $H$. pylori infection. In $65 \%$ of the patients, sequential and traditional triple therapies had equal efficacy in the treatment of $H$. pylori infection. Resistance to metronidazole and clarithromycin for strains of $H$. pylori is not uncommon. $^{20}$

According to meta-analytical study in a Cochrane review, using high-dose STT therapy showed less efficacy than SEQ therapy in eradication of $H$. pylori. And concluded that both regimens could not achieve favorable efficiency ( $\geq 90 \%$ abolition rate). ${ }^{21}$

Yang et al., through their study, concluded that high-dose drug therapy has higher efficacy than standard regimens in the eradication of $H$. pylori. $^{22}$

Kim et al. studied new advances in abolition rates in $\mathrm{H}$. pylori by first-line triple (one PPI along with two antibiotics) treatment, and the associated factor in eradication of $H$. pylori has been reduced over the past 10 years. They further concluded that the measures of antibiotic resistance in $\mathrm{H}$. pylori infection have amplified, mainly with reverence to clarithromycin. ${ }^{23}$

In a phase III, randomized, double-blinded study by Murakami et al., vonoprazan (potassium-competitive acid blocker), as a part of first-line and second-line triple treatment for $\mathrm{H}$. pylori abolition, was studied among 650 patients and reported that vonoprazan has high efficacy as part of first-line triple-therapy and also as part of second-line triple treatment for eradication of $H$. pylori-related peptic ulcer. ${ }^{24}$ 
The role of addition of bismuth (14-day triple therapy with bismuth) in improving the eradication rates despite the problem of antimicrobial resistance was noted. The bismuth effect added an additional $30-40 \%$ to the success of treatment of resistant infections. $^{25}$

Meta-analysis of many other randomized controlled trials showed that $H$. pylori abolition treatment to avoid gastric cancer found out that $H$. pylori decreases the occurrence of carcinoma of stomach in asymptomatic Asian individuals. ${ }^{26}$

Zhang et al. found that the addition of one probiotic to standard treatment was found to improve the $H$. pylori eradication rate. ${ }^{27}$

"The Toronto Consensus" stated that the ideal cure of H. pylori infection requires cautious consideration of local antibiotic resistance and the abolition pattern. The quadruple therapy "PAMC" (one PPI and three antibiotics-amoxicillin, metronidazole, and clarithromycin) or "PBMT" (one PPI, one bismuth compound and two antibiotics-metronidazole and tetracycline) should play an additional important function in eradication of H. pylori. ${ }^{18}$

\section{Limitations}

- Study with larger sample size will be of better accuracy.

\section{Conclusion}

Among the 30 patients who were administered regimen I: OCA (omeprazole-20 mg bid, clarithromycin-500 mg bid, amoxicillin $1,000 \mathrm{mg}$ bid for 2 weeks), H. pylori was eradicated in 27 (90\%) patients. Among the 30 patients who were administered regimen II: OCM (omeprazole $20 \mathrm{mg}$ bid, clarithromycin $500 \mathrm{mg}$ bid, and metronidazole $400 \mathrm{mg}$ bid for 2 weeks), H. pylori was eradicated in 28 (93.3\%) patients. This difference was not statistically significant with $p$ value of 0.323 and it was observed that the efficacy of the both regimens remains significantly equal. Both the regimens can be suggested for abolition of $H$. pylori. However, it was observed that regimen II was less costly than regimen I. Regimen I is also suggested for those $H$. pylori-infected patients who are responsive to penicillin.

\section{References}

1. WHO. Helicobacter pylori [Internet]. WHO. World Health Organization; 2013.

2. Atherton JC. The pathogenesis of Helicobacter pylori-induced gastroduodenal diseases. Annu Rev Pathol Mech Dis 2006;1(1):63-96. DOI: 10.1146/annurev.pathol.1.110304.100125.

3. Kusters JG, van Vliet AHM, Kuipers EJ. Pathogenesis of Helicobacter pylori infection. Clin Microbiol Rev 2006;19(3):449-490. DOI: 10.1128/ CMR.00054-05.

4. Wu C, Kuo KN, Wu M, Chen Y, Wang C, Lin J. Early Helicobacter pylori eradication decreases risk of gastric cancer in patients with peptic ulcer disease. Gastroenterology 2009;137(5):1641-1648.e2. DOI: 10.1053/j.gastro.2009.07.060.

5. Kale-Pradhan PB, Landry HK, Sypula WT. Esomeprazole for acid peptic disorders. Ann Pharmacother 2002;36(4):655-663. DOI: 10.1345/ aph.1A104.

6. Johnson DA. Review of esomeprazole in the treatment of acid disorders. Expert Opin Pharmacother 2003;4(2):253-264. DOI: 10.1517/14656566.4.2.253 Johnson TJ, Hedge DD. Esomeprazole: a clinical review. Am J Health Syst Pharm 2002;59(14): 1333-1339.

7. Scott LJ, Dunn CJ, Mallarkey G, Sharpe M. Esomeprazole: a review of its use in the management of acid-related disorders. Drugs
2002;62(10):1503-1538. DOI: 10.2165/00003495-20026210000006.

8. Spencer CM, Faulds D. Esomeprazole. Drugs 2000;60(2):321-329. DOI: 10.2165/00003495-200060020-00006discussion 330-1.

9. Gisbert JP. Potent gastric acid inhibition in Helicobacter pylori eradication. Drugs 2005;65(Suppl. 1):83-96. DOI: 10.2165/00003495200565001-00012.

10. Röhss K, Hasselgren G, Hedenström H. Effect of esomeprazole 40 $\mathrm{mg}$ vs omeprazole $40 \mathrm{mg}$ on 24-hour intragastric $\mathrm{pH}$ in patients with symptoms of gastroesophageal reflux disease. Dig Dis Sci 2002;47(5):954-958. DOI: 10.1023/a:1015009300955.

11. Kahrilas PJ, Falk GW, Johnson DA, Schmitt C, Collins DW, Whipple $J$, et al. Esomeprazole improves healing and symptom resolution as compared with Omeprazole in reflux oesophagitis patients: a randomized controlled trial. The esomeprazole study investigators. Aliment Pharmacol Ther 2000;14(10):1249-1258. DOI: 10.1046/j.13652036.2000.00856.x

12. Lind T, Rydberg L, Kylebäck A, Jonsson A, Andersson T, Hasselgren G, et al. Esomeprazole provides improved acid control vs. Omeprazole in patients with symptoms of gastro-oesophageal reflux disease. Aliment Pharmacol Ther 2000;14(7):861-867. DOI: 10.1046/j.13652036.2000.00813.x.

13. Gatta L, Perna F, Figura N, Ricci C, Holton J, D'anna L, et al. Antimicrobial activity of esomeprazole versus Omeprazole against Helicobacter pylori. J Antimicrob Chemother 2003;51(2):439-442. DOI: 10.1093/jac/dkg085.

14. Malfertheiner P, Megraud F, O'Morain C, Bazzoli F, El-Omar E, Graham $\mathrm{D}$, et al. Current concepts in the management of Helicobacter pylori infection: the Maastricht III consensus report. Gut 2007;56(6):772-781. DOI: 10.1136/gut.2006.101634.

15. Malfertheiner P, Megraud F, O'Morain CA, Atherton J, Axon ATR, Bazzoli $F$, et al. Management of Helicobacter pylori infectionthe Maastricht IV/Florence consensus report. Gut [Internet] 2012;61(5):646-664. DOI: 10.1136/gutjnl-2012-302084.

16. Malfertheiner P, Megraud F, O'Morain CA, Gisbert JP, Kuipers EJ, Axon AT, et al. Management of Helicobacter pylori infection - the Maastricht V/Florence consensus report. Gut [Internet] 2017;66(1):6-30. DOI: 10.1136/gutjnl-2016-312288.

17. Khanal S, Rao BS, Sharma Y, Khan GM, Makaju R. Comparative study between two triple therapy regimens on eradication of Helicobacter pylori (hp). Kathmandu University Journal Of Science, Engineering and Technology, vol. l; 2005.

18. Fallone CA, Chiba N, van Zanten SV, Fischbach L, Gisbert JP, Hunt RH, et al. The Toronto consensus for the treatment of Helicobacter pylori infection in adults. Gastroenterology 2016;151(1):51-69.e14. DOI: 10.1053/j.gastro.2016.04.006.

19. Molina-Infante J, Lucendo AJ, Angueira T, Rodriguez-Tellez M, PerezAisa A, Balboa A, et al. Optimised empiric triple and concomitant therapy for Helicobacter pylori eradication in clinical practice: the OPTRICON study. Aliment Pharmacol Ther 2015;41(6):581-589. DOI: 10.1111/apt.13069.

20. Alsohaibani F, Al Ashgar H, Al Kahtani K, Kagevi I, Peedikayil M, Alfadda A, et al. Prospective trial in Saudi Arabia comparing the 14-day standard triple therapy with the 10-day sequential therapy for treatment of Helicobacter pylori infection. Saudi J Gastroenterol 2015;21(4):220-225. DOI: 10.4103/1319-3767.161647.

21. Nyssen OP, McNicholl AG, Megraud F, Savarino V, Oderda G, Fallone $C A$, et al. Sequential versus standard triple first-line therapy for Helicobacter pylori eradication. Cochrane Database of Systematic Reviews. John Wiley \& Sons, Ltd; 2016.

22. Yang J-C, Lin C-J, Wang H-L, Chen J-D, Kao JY, Shun C-T, et al. High-dose dual therapy is superior to standard first-line or rescue therapy for Helicobacter pylori infection. Clin Gastroenterol Hepatol 2015;13(5):895-905.e5. DOI: 10.1016/j.cgh.2014.10.036.

23. Kim SE, Park MI, Park SJ, Moon W, Choi YJ, Cheon JH, et al. Trends in Helicobacter pylori eradication rates by first-line triple therapy 
and related factors in eradication therapy. Korean J Intern Med 2015;30(6):801-807. DOI: 10.3904/kjim.2015.30.6.801.

24. Murakami K, Sakurai Y, Shiino M, Funao N, Nishimura A, Asaka M. Vonoprazan, a novel potassium-competitive acid blocker, as a component of first-line and second-line triple therapy for Helicobacter pylori eradication: a phase III, randomised, double-blind study. Gut 2016;65(9):1439-1446. DOI: 10.1136/gutjnl-2015-311304.

25. Dore MP, Lu H, Graham DY. Role of bismuth in improving Helicobacter pylori eradication with triple therapy. Gut 2016;65(5):870-878. DOI: 10.1136/gutjnl-2015-311019.
26. Ford AC, Forman D, Hunt RH, Yuan Y, Moayyedi P. Helicobacter pylori eradication therapy to prevent gastric cancer in healthy asymptomatic infected individuals: systematic review and metaanalysis of randomised controlled trials. BMJ 2014;348(may20 1):g3174. DOI: $10.1136 / \mathrm{bmj} . g 3174$.

27. Zhang M-M, Qian W, Qin Y-Y, He J, Zhou Y-H. Probiotics in Helicobacter pylori eradication therapy: a systematic review and meta-analysis. World J Gastroenterol 2015;21(14):4345-4357. DOI: 10.3748/wjg.v21. i14.4345. 